\title{
HIV prevalence at birth in very low-birthweight infants
}

\author{
V John, MB ChB, FCPaed (SA); K Harper, MB ChB, DCH, FCPaed (SA) \\ Department of Paediatrics, Frere Hospital and Walter Sisulu University, East London, South Africa
}

Corresponding author: V John (jeffveenajohn@gmail.com)

\begin{abstract}
Background. South Africa implemented lifelong antiretroviral therapy (ART) for prevention of mother-to-child transmission (PMTCT) of HIV to reduce the risk of vertical HIV transmission. The rate of in utero transmission of HIV in very low-birthweight $($ VLBW $)(<1500 \mathrm{~g})$ infants, which is a high-risk population, is largely unknown.

Objectives. To determine the rate of in utero transmission in VLBW infants and to describe the characteristics of the infants infected with HIV.

Methods. This was a retrospective cross-sectional study of VLBW infants exposed to HIV, over a two-year period, at two hospitals in the Eastern Cape. Relevant data (maternal and infant) were extracted from medical records and analysed. Descriptive statistics are reported for all variables as means, medians and standard deviations for continuous numerical variables, and as percentages for categorical data. A $p$-value $<0.05$ was considered significant.

Results. The hospital registers identified 273 VLBW infants; nine were excluded. Four infants (1.5\%) were HIV polymerase chain reaction (PCR)-positive. The viral load was significantly higher among mothers of infants who tested HIV PCR-positive (Mann-Whitney $U$ test; $p=0.001$ ). HIV-positive infants had a higher median weight (1 $333 \mathrm{~g} \mathrm{v.} 1190 \mathrm{~g}$ ) at birth; and mothers of HIV-positive infants were slightly older (31 v. 28 years). Both of these characteristics were not statistically significant.

Conclusion. The study demonstrates a low prevalence of HIV in a high-risk group of VLBW infants. This rate is comparable to the national prevalence for all infants. Clinicians should aim for HIV viral suppression throughout pregnancy to achieve the global target of elimination of mother-to-child transmission.
\end{abstract}

S Afr J Child Health 2020;14(3):129-132. https://doi.org/10.7196.SAJCH.2020.v14i3.1687

The human immunodeficiency virus (HIV) is an ongoing threat to the health and wellbeing of children worldwide. In 2013, 1.3 million women living with HIV gave birth. ${ }^{[1]}$ A closer look at these figures shows that $85 \%$ of all pregnant women, worldwide, living with HIV, reside in sub-Saharan Africa. ${ }^{[1]}$ Since implementation of the highly effective prevention of mother-to-child transmission (PMTCT) programme in 2004, the incidence of vertically infected infants has declined. Despite this progress, an estimated 12000 children were newly infected with HIV owing to mother-tochild transmission in South Africa (SA) in 2016 alone. ${ }^{[2]}$ By promoting early diagnosis and, when necessary, timeous initiation of antiretroviral therapy (ART), one can reduce mortality, disease progression and neurodevelopmental impairment in children infected by HIV. ${ }^{[3]}$

Mother-to-child transmission of HIV can occur in utero, intrapartum and via breastfeeding. In April 2015, the SA PMTCT guidelines recommended that all infants should be tested for HIV infection at birth. ${ }^{[4]}$ In 2016, the overall (all weight categories) transmission rate at birth was $1.1 \% \cdot{ }^{[5]}$ In utero HIV transmission rates in very low-birthweight (VLBW) infants is largely unknown, and more so in the Eastern Cape. In 2017, 31\% of all VLBW infants born at East London public sector hospitals were HIV exposed. ${ }^{[6]}$ Knowledge concerning this group of infants is important, as VLBW infants are at increased risk of in utero HIV transmission. ${ }^{[7-10]}$

We aimed to report the prevalence of HIV infection in infants weighing less than $1500 \mathrm{~g}$ (VLBW infants) at birth and to describe the characteristics of those infants who had a positive HIV polymerase chain reaction (PCR) test.

\section{Methods}

This was a retrospective cross-sectional study performed at Frere Hospital, East London, and Cecilia Makiwane Hospital, Mdantsane, SA, during a two-year study period between 1 May 2016 and 31 April 2018. Both hospitals follow current national paediatric guidelines in testing all HIV-exposed infants for HIV infection at birth. The qualitative HIV PCR assay used for infant HIV testing was the Roche Cobas Ampliprep/Cobas TaqMan (CAP/CTM).

VLBW infants, i.e. weighing $<1500 \mathrm{~g}$ at birth, born to women living with HIV, were included in the study. Infants $<500 \mathrm{~g}$ were excluded from the study as they are not admitted to the nursery owing to poor viability. Information was extracted from neonatal and hospital records and entered into an Excel (Microsoft Corp., USA) database. Data captured included maternal information (age, current ART details such as regimen, number of months on ART in relation to delivery and HIV viral load) and infant details (birthweight, HIV PCR result and Ballard gestational score).

Ethics approval was granted by the Walter Sisulu University (WSU) Human Research Ethics Committee (ref. no. 039/2018). The clinical governance of the two hospitals gave permission for implementation of the study protocol. As this was a retrospective folder review, the need for informed consent was waived.

Data were analysed using Excel (Microsoft Corp., USA) and the Statistical Package for Social Sciences (SPSS), version 25 (StataCorp., USA). Descriptive statistics are reported for all variables as means and standard deviations for continuous numerical variables, and as percentages for categorical data. For all tests, a $p$-value $<0.05$ was considered significant. 


\section{Results}

The registers identified 273 HIV-exposed infants weighing $<1500 \mathrm{~g}$ over the study period. Nine patients were excluded owing to incomplete data, of whom four died prior to their HIV PCR. Table 1 displays the characteristics and outcomes of the 264 infants weighing $<1500 \mathrm{~g}$ at birth. Of the 264 infants, half had mothers who received ART prior to pregnancy, $16(6 \%)$ received no treatment before delivery, and the others were initiated on treatment during pregnancy. The majority of mothers $(>80 \%)$ received more than three months of ART prior to delivery and were on first-line treatment $(88 \%)$. Viral load (VL) was suppressed $(<1000$ copies $/ \mathrm{mL})$ in 155 mothers (59\%), >1 000 copies/mL in 59 (22\%), and either not yet tested or not available in $50(19 \%)$.

Of the 264 infants, all had a HIV PCR test performed within the first 48 hours of life, of which four (1.5\%) were HIV PCR-positive. Mothers of HIV-infected infants tended to be slightly older (28.0 v. 30.5 years). Infants who were HIV-positive tended to weigh more than infants who were HIV-negative (Table 1). These differences were not statistically significant. All four mothers of HIV-positive infants were on first-line treatment, and three received ART prior to pregnancy (Table 2). All of these mothers had a very high viral load (ranging from 29900 to 132 867), which was significantly higher than mothers of HIV-negative infants (Mann-Whitney $U$ test; $p=0.001$ ).

\section{Discussion}

The most recent SA guidelines on PMTCT and management of HIV in children, published in 2018, are in keeping with the World Health Organization (WHO) strategy of early diagnosis for HIVexposed children. ${ }^{[11,12]}$ The current guidelines recommend the testing of all HIV-exposed infants at birth to detect in utero transmission. Thereafter, at 10 weeks, a repeat HIV PCR is performed. This HIV PCR at 10 weeks will detect virtually all in utero and intrapartum transmission, as well as early breast-milk transmission of HIV as long as ART prophylaxis has been discontinued by six weeks of age. This proactive strategy allows very early infant diagnosis and, if necessary, earlier initiation of ART. ${ }^{[13,14]}$

With widespread acceptance of the PMTCT programme, the overall SA HIV transmission rate has improved from $4.1 \%$ in 2010 to $2.3 \%$ in $2012 .{ }^{[15]}$ Data extracted from the National Health Laboratory Services (NHLS) database showed the number of HIV PCRs done on infants at birth has greatly improved from 39\% to $93 \%$ from June 2015 to May 2016. During this period, the national HIV transmission rate was $1.1 \%$ at birth in all HIV-exposed infants. ${ }^{[5]}$

VLBW infants have a higher risk of vertical transmission of HIV. ${ }^{[16]}$ We report a HIV transmission rate of $1.5 \%$, with four of 264 HIVexposed VLBW infants testing positive. Despite a higher risk of HIV transmission reported in the literature previously, mostly prior to the implementation of option B plus where pregnant women tested HIV-

Table 1. Characteristics and outcomes of VLBW infants

\begin{tabular}{|c|c|c|c|}
\hline Characteristics & $\begin{array}{l}\text { Whole sample } \\
(N=264), n(\%)^{*}\end{array}$ & $\begin{array}{l}\text { HIV PCR-negative } \\
(n=260), n(\%)^{*}\end{array}$ & $\begin{array}{l}\text { HIV PCR-positive } \\
(n=4), n(\%)^{*}\end{array}$ \\
\hline \multicolumn{4}{|l|}{ Maternal details } \\
\hline Age (years), median (IQR) & $28(24-33)$ & $28(24-33)$ & $31(27-35)$ \\
\hline \multicolumn{4}{|l|}{ HIV diagnosis } \\
\hline Prior to pregnancy & $132(50)$ & $129(50)$ & $3(75)$ \\
\hline During pregnancy & $116(44)$ & $115(44)$ & $1(25)$ \\
\hline Peripartum & $16(6)$ & $16(6)$ & 0 \\
\hline Number of months on & $12(3-22)$ & $12(3-22)$ & \\
\hline \multicolumn{4}{|l|}{ ART $(\text { median }(\mathrm{IQR}))^{+}$} \\
\hline \multicolumn{4}{|l|}{ Duration, months } \\
\hline$<3$ months & $35(13)$ & $35(13)$ & 0 \\
\hline$>3$ months & $213(81)$ & $209(80)$ & $4(100)$ \\
\hline No treatment & $16(6)$ & $16(6)$ & 0 \\
\hline \multicolumn{4}{|l|}{ HIV viral load (copies/mL) } \\
\hline Absolute (median (IQR)) & $43(0-1493)$ & $40(0-1097)$ & $75208(35717-123962)$ \\
\hline$<1000$ & $155(59)$ & $155(60)$ & $0(0)$ \\
\hline$>1000$ & $59(22)$ & $55(21)$ & $4(100)$ \\
\hline No VL but indicated & $18(7)$ & $18(7)$ & $0(0)$ \\
\hline Not yet indicated ${ }^{\ddagger}$ & $32(12)$ & $32(12)$ & $0(0)$ \\
\hline \multicolumn{4}{|l|}{ ART } \\
\hline 1st line & $235(89)$ & $231(89)$ & $4(100)$ \\
\hline 2nd line & $11(4)$ & $11(4)$ & 0 \\
\hline No treatment & $16(6)$ & $16(6)$ & 0 \\
\hline AZT only & $2(1)$ & $2(1)$ & 0 \\
\hline \multicolumn{4}{|l|}{ Infant details } \\
\hline GA (weeks), median (IQR) & $32(31-35)$ & $32(31-35)$ & $35(32-36)$ \\
\hline Birthweight, g (median (IQR)) & $1195(1000-1350)$ & $1190(1000-1348)$ & $1333(1105-1459)$ \\
\hline \multicolumn{4}{|c|}{$\begin{array}{l}\text { VLBW = very low-birthweight; PCR = polymerase chain reaction; IQR = interquartile range; } A R T=\text { antiretroviral treatment; AZT = zidovudine; GA = gestational age. } \\
\text { *Unless otherwise specified. } \\
\text { 'The exact number of months in three PCR-negative patients was not documented; however, all three had been on ART for more than three months. } \\
\text { FV was not determined as these mothers had been on treatment for less than three months. }\end{array}$} \\
\hline
\end{tabular}


Table 2. Characteristics and outcomes of HIV-infected VLBW infants

\begin{tabular}{|c|c|c|c|c|}
\hline Clinical variables & Baby 1 & Baby 2 & Baby 3 & Baby 4 \\
\hline Maternal age, years & 31 & 30 & 37 & 26 \\
\hline Infant's GA, weeks & 31 & 35 & 34 & 36 \\
\hline Birthweight, g & 1300 & 1040 & 1490 & 1365 \\
\hline ARV commencement & During pregnancy & Prior to pregnancy & Prior to pregnancy & Prior to pregnancy \\
\hline $\begin{array}{l}\text { Number of months on } \\
\text { ART }\end{array}$ & 3 & 24 & Unknown & 14 \\
\hline HIV viral load (copies/mL) & 53168 & 29900 & 132867 & 97247 \\
\hline ART & 1st line & 1st line & 1st line & 1st line \\
\hline Antenatal course & $\begin{array}{l}\text { Booked at } 12 \text { weeks prior } \\
\text { to delivery } \\
\text { Non-compliant on ART } \\
\text { Known substance abuse } \\
\text { during pregnancy }\end{array}$ & $\begin{array}{l}\text { Diagnosed with HIV two } \\
\text { years prior to booking } \\
\text { Non-compliant on ART }\end{array}$ & $\begin{array}{l}\text { Diagnosed with HIV } \\
\text { prior to pregnancy } \\
\text { Previously, VL was } \\
\text { suppressed; however, non- } \\
\text { compliant for } 6 \text { months } \\
\text { prior to booking } \\
\text { Only booked } 3 \text { days prior } \\
\text { to delivery }\end{array}$ & $\begin{array}{l}\text { Diagnosed with vaginal } \\
\text { warts and Kaposi's sarcoma } \\
\text { Planned for caesarean } \\
\text { section, but delivered } \\
\text { vaginally } \\
\text { Non-compliant on ART }\end{array}$ \\
\hline Infant's outcome & $\begin{array}{l}\text { Received dual prophylaxis } \\
\text { (AZT/NVP) since birth } \\
\text { Started AZT/3TC/NVP } \\
\text { on day } 7 \text { once HIV PCR } \\
\text { positive } \\
\text { VL on discharge was } \\
479 \text { copies/mL }\end{array}$ & $\begin{array}{l}\text { Received dual prophylaxis } \\
\text { (AZT/NVP) since birth } \\
\text { Died on day } 6 \text { of life owing } \\
\text { to severe necrotising } \\
\text { enterocolitis } \\
\text { ART never commenced }\end{array}$ & $\begin{array}{l}\text { Received dual prophylaxis } \\
\text { (AZT/NVP) since birth } \\
\text { Started AZT/3TC/NVP } \\
\text { on day } 10 \text { once HIV PCR } \\
\text { positive } \\
\text { VL not done prior to } \\
\text { discharge - lost to follow- } \\
\text { up }\end{array}$ & $\begin{array}{l}\text { Received dual prophylaxis } \\
\text { (AZT/NVP) since birth. } \\
\text { Initial HIV test was } \\
\text { indeterminate - repeat test } \\
\text { was positive } \\
\text { Commenced AZT/3TC/ } \\
\text { NVP on day } 22 \text { of life } \\
\text { VL } 770 \text { copies/mL at } \\
3 \text { months }\end{array}$ \\
\hline
\end{tabular}

$\mathrm{GA}=$ gestational age; $\mathrm{VLBW}=$ very low-birthweight $\mathrm{ART}=$ antiretroviral therapy $\mathrm{PCR}=$ polymerase chain reaction; $\mathrm{VL}=\mathrm{viral}$ load $; \mathrm{AZT}=$ zidovudine; $\mathrm{NVP}=\mathrm{nevirapine} ;$ $3 \mathrm{TC}=$ lamivudine.

positive are initiated on lifelong ART, the HIV transmission rate in VLBW infants in our population is comparable to the national HIV transmission rate in all infants, irrespective of weight.

Transmission rates between $1.6 \%$ and $7.7 \%$ have been reported; Tooke et al. ${ }^{[8]}$ in 2013, did a cross-sectional retrospective review of extremely low-birthweight infants $(<1000 \mathrm{~g})$ to determine the HIV transmission rate at six weeks of age. They reported a $2.7 \%$ risk of transmission. However, this study was limited. Twenty-seven percent ( $n=14 / 51)$ of infants had died prior to the six-week HIV test and, as a result, their HIV transmission risk was undetermined. Levin et al. ${ }^{[16]}$ in 2017, looked into the in utero transmission at birth in VLBW infants; six percent $(n=5 / 82)$ of infants tested positive. All of the mothers of HIV-infected infants had a high viral load. This risk of transmission is markedly higher than in our setting. Lilian et al. ${ }^{[17]}$ reported a transmission rate of $1.6 \%$ after testing 6467 newborns within 48 hours of life, irrespective of weight. This study included a large number of infants and, even though their weight and risk status were not discussed, the transmission rate was similar to that of our population.

Pillay et al. ${ }^{[9]}$ in 2014 showed a $7.7 \%$ in utero HIV infection rate in infants who were HIV exposed. This retrospective study had a transmission rate higher than other reports in the literature, in the ART era. This finding can be attributed to a selection bias, where only the high-risk study population group was tested for HIV at birth as per national guidelines at that time. ${ }^{[9]}$ Dunning et al. ${ }^{[10]}$ in 2017 divided infants exposed to HIV into two groups: high risk and low risk. High-risk infants included preterm infants, infants born to mothers with a high maternal VL, or a recent maternal HIV infection. Neonates in the high-risk group all had a HIV PCR test at birth. An equal number of low-risk HIV-exposed infants were then included to compare transmission at six weeks of age. However, in this low-risk group, a birth HIV PCR test was not performed, as per the PMTCT guidelines at the time. They reported a transmission rate of $3.8 \%$ at birth in the high-risk group, which is over double the risk in our study that included only VLBW babies who are at higher risk of perinatal HIV infection. A subgroup analysis with birthweight categories may have assisted in looking for a true comparison in transmission risks. Dunning et al. ${ }^{[10]}$ suggested that targeted HIV testing of a high-risk population will have a greater and more costeffective yield of positive results but the definition of high-risk should possibly be related to maternal ART use and VL.

The mothers of all four infants who had a positive HIV PCR had a high maternal HIV viral load. A high maternal viral load is associated with increased risk of vertical HIV transmission, which is supported by the literature. ${ }^{[18,19]}$ Of the various factors influencing vertical HIV transmission, a high maternal HIV VL $>1000$ copies $/ \mathrm{mL}$ has been shown to be the most significant risk factor. ${ }^{[18]}$ Unfortunately, owing to the limited number of positive infants, we were not able to explore this association to further fully determine if a high maternal HIV VL was a causative factor for vertical HIV transmission in this study. Maternal diagnosis of HIV infection during the pregnancy, use of maternal ART $<8$ weeks prior to delivery, treatment interruption or poor compliance, and concurrent opportunistic infections all contribute to not achieving virological suppression and, therefore, increased risk of transmission of HIV. ${ }^{[20]}$ Red-flagging these mothers early in pregnancy and swiftly switching to the more robust second line of ART would enable the decline of in utero transmission. 
Mothers of HIV-positive infants tended to be slightly older than the HIV-negative group, although Taha et al. ${ }^{[21]}$ reported that mothers who were younger were at higher risk of transmitting HIV to their infants. The trend shown in our study may not reflect the actual relationship between maternal age and HIV infections, as the result was statistically insignificant.

Infants who tested HIV-positive weighed more than infants who were HIV-exposed but negative. Although this difference was not statistically significant and difficult to compare owing to a small study population, it contradicts studies which suggest that HIVinfected infants tend to have a lower birthweight ${ }^{[20]}$ but may also agree with studies which suggest that HIV transmission occurs later in pregnancy. ${ }^{[22-24]}$

There are some limitations to the present study that must be considered. As previously acknowledged, nine infants were excluded from the study. Four of these infants died prior to the birth PCR being performed and their final HIV status was unknown. As per national PMTCT guidelines, all infants received their HIV PCR at birth (within 48 hours). However, none of the infants was tested immediately post delivery, prior to the first dose of ART being administered. This single dose of nevirapine has been shown to reduce the already low VL, rendering it undetectable, ${ }^{[25]}$ which may introduce false negative results. Ideally, all infants with a negative HIV PCR at birth need to be followed up with a repeat HIV PCR at 10 weeks to determine overall perinatal transmission; these results were not recorded. Further studies are needed to determine the overall perinatal transmission rate and to further isolate risk factors, both maternal and neonatal, resulting in vertical HIV transmission.

\section{Conclusion}

The ever-evolving PMTCT programme has reduced transmission rates significantly. The low rate of in utero transmission of HIV among VLBW infants in the present study's setting is comparable to the national prevalence for all infants.The present study shows the importance of VL suppression and aggressive management of elevated VL in pregnant women to prevent vertical transmission. Clinicians managing HIV-infected women should aim for virological suppression throughout pregnancy and delivery to achieve the global target of elimination of mother-to-child transmission in the country. ${ }^{[12]}$ Further studies are needed to determine the HIV transmission rate in VLBW infants.

Declaration. This manuscript was submitted as part of an MMed dissertation.

Acknowledgements. We thank Mrs Michelle Henry for her assistance with the statistical analysis.

Author contributions. VJ - main author; $\mathrm{KH}$ - supervisor.

Funding. A Discovery Academic Research Grant was received for this research.

Conflicts of interest. None.

1. The GAP report. Children and Pregnant Women Living with HIV. 2014 http://www.unaids.org/sites/default/files/media_asset/09_Childrenand pregnantwomenlivingwithHIV.pdf (accessed 25 January 2019).

2. UNAIDS Statistics South Africa. Geneva: UNAIDS; 2016. http://www.unaids. org/en/regionscountries/countries/southafrica (accessed 1 April 2019).

3. Violari A, Cotton MF, Gibb DM, et al. Early antiretroviral therapy and mortality among HIV-infected infants. N Engl J Med 2008;359(21):2233-2244. https:/l doi.org/10.1056/nejmoa0800971
4. South African National Department of Health. National Consolidated Guidelines for the Prevention of Mother-To-Child Transmission of HIV (PMTCT) and the Management of HIV in Children, Adolescents and Adults. Pretoria: DoH (SA); April 2015:1-128. www.doh.gov.za (accessed 17 January 2019).

5. Moyo F, Haeri Mazanderani A, Barron P, et al. Introduction of routine HIV birth testing in the South African National Consolidated Guidelines. Pediatr Infect Dis J 2018;37(6):559-563. https://doi.org/10.1097/inf.0000000000001840

6. Frere Perinatal Problem Identification Programme Data. East London: Frere PPIP Data; 2017

7. Lilian RR, Kalk E, Bhowan K, et al. Early diagnosis of in utero and intrapartum HIV infection in infants prior to 6 weeks of age. J Clin Microbiol 2012;50(7):2373-2377.

8. Tooke L, Horn AR, Harrison MC. HIV transmission to extremely low birth weight infants. Pediatr Infect Dis 2013;32(1):36-38.

9. Pillay S, Kroon M, Hsiao M, Nuttall J. Neonatal HIV Case Series: Challenges in Diagnosis and Management. 2014. http://www.paediatrics.uct.ac.za/sites/ default/files/image_tool/images/38/J Nuttall - PDF presentation.pdf (accessed 2 April 2018).

10. Dunning L, Kroon M, Fourie L, Ciaranello A, Myer L. Impact of birth HIVPCR testing on the uptake of follow-up early infant diagnosis services in Cape Town, South Africa. Pediatr Infect Dis J 2017;36(12):1159-1164. https://doi.org /10.1097\%2FINF.0000000000001677

11. National Department of Health. Paediatric Standard Treatment Guidelines and Essential Medicines List. Pretoria: NDoH; 2017. http://www.health.gov $\mathrm{za} /$ index.php/standard-treatment-guidelines-and-essential-medicines-list/ category/456-hospital-level-paediatrics (accessed 28 July 2020).

12. World Health Organization. Global guidance on criteria and processes for validation: Elimination of mother-to-child transmission of HIV and syphilis. Monitoring and evaluation. 2nd ed. 2017. https://apps.who.int/iris/bitstream/ handle/10665/112858/9789241505888_eng.pdf;jsessionid=FA543EA6AC7087 F3820DE8F944A690D8? sequence=1 (accessed 25 Jan 2019)

13. Lilian RR, Kalk E, Technau K-G, Sherman GG. Birth diagnosis of HIV infection in infants to reduce infant mortality and monitor for elimination of motherto-child transmission. Pediatr Infect Dis J 2013;32(10):1080-1085. https://doi. org/10.1097/inf.0b013e318290622e

14. National Department of Health. The South African Antiretroviral Treatment Guidelines 2013. Pretoria: NDoH; 2013. http://www.kznhealth.gov.za/ medicine/2013 art_guidelines.pdf (accessed 1 April 2019).

15. Sherman GG, Mazanderani AH, Barron P, et al. Toward elimination of motherto-child transmission of HIV in South Africa: How best to monitor early infant infections within the Prevention of Mother-to-Child Transmission Program. J Glob Health 2017;7(1). https://doi.org/10.7189\%2Fjogh.07.010701

16. Levin C, Le Roux DM, Harrison MC, Tooke L. HIV transmission to premature very low birth weight infants. Pediatr Infect Dis J 2017;36(9):860-862. https:// doi.org/10.1097/INF.0000000000001611

17. Lilian RR, Kalk E, Technau K-G, Sherman GG. Birth diagnosis of HIV infection in infants to reduce infant mortality and monitor for elimination of motherto-child transmission. Pediatr Infect Dis J 2013;32(10):1080-1085. https://doi. org/10.1097/inf.0b013e318290622e

18. Townsend CL, Byrne L, Cortina-Borja M, et al. Earlier initiation of ART and further decline in mother-to-child HIV transmission rates, 2000-2011. AIDS 2014;28(7):1049-1057. https://doi.org/10.1097/qad.0000000000000212

19. Bera E, Jwacu N, Pauls F, Mancotywa T, Ngcelwane N, Hlati Y. Risk factors for perinatal HIV-1 transmission in pregnant women requiring lifelong antiretroviral therapy: A longitudinal study at a tertiary hospital in South Africa. S Afr J Obstet Gynaecol 2010;16(1):6-13.

20. Kroon M. Recognising and managing increased HIV transmission risk in newborns. S Afr J HIV Med 2015;16(1):7. https://doi.org/10.4102/sajhivmed. v16i1.371

21. Taha TE, James MM, Hoover DR, et al. Association of recent HIV infection and in-utero HIV-1 transmission. AIDS 2011;25(11):1357-1364. https://doi.org/10. 1097\%2FQAD.0b013e3283489d45

22. Kourtis AP, Lee FK, Abrams EJ, Jamieson DJ, Bulterys M. Mother-to-child transmission of HIV-1: Timing and implications for prevention. Lancet Infect Dis 2006;6(11):726-732. https://doi.org/10.1016/s1473-3099(06)70629-6

23. Volmink J, Marais B. HIV: Mother-to-child transmission. 2008. https://www. ncbi.nlm.nih.gov/pmc/articles/PMC2907958/pdf/2008-0909.pdf (accessed 1 April 2019).

24. WarszawskiJ, Tubiana R, Le Chenadec J, et al. Mother-to-child HIV transmission despite antiretroviral therapy in the ANRS French Perinatal Cohort. AIDS 2008;22(2):289-299. https://doi.org/10.1097/qad.0b013e3282f3d63c

25. Mphatswe W, Blanckenberg N, Tudor-Williams G, et al. High frequency of rapid immunological progression in African infants infected in the era of perinatal HIV prophylaxis. AIDS 2007;21(10):1253-1261. https://doi. org/10.1097/qad.0b013e3281a3bec2

Accepted 30 April 2020. 